\title{
A Prototype Recombinant Vaccine Against Respiratory Syncytial Virus and Parainfluenza Virus Type 3
}

\author{
Run-Pan Du, Gail E.D. Jackson, Philip R. Wyde', Wei-Yao Yan, Qijun Wang, Lucy Gisonni, Sonia E. Sanhueza,
} Michel H. Klein, and Mary E. Ewasyshyn*

Connaught Centre for Biotechnology Research, 1755 Steeles Ave. West, Willowdale, Ontario, Canada, M2R 3T4. 'Department of Microbiology and Immunology, Baylor College of Medicine, Houston, Texas, USA, 77030. *Corresponding author.

We have produced a genetically-engineered chimeric protein composed of the external domains of the respiratory syncytial virus (RSV) fusion (F) protein and the parainfluenza virus type 3 (PIV-3) hemagglutinin-neuraminidase (HN) protein in insect cells using the baculovirus expression system. The yield of the soluble chimeric $\mathbf{F}_{\mathrm{RSV}}-\mathrm{HN}_{\mathrm{PIV}-3}$ protein could be increased approximately 2 -fold by using Trichoplasia ni (High Five) insect cells in place of Spodoptera frugiperda (Sf9) for expression. The chimeric protein, purified from the supernatant of baculovirus-infected High Five cells by immunoaffinity chromatography was correctly processed at the F2-F1 proteolytic cleavage site. Immunochemical analysis of the chimera with a panel of anti-F and anti-HN monoclonal antibodies suggested that the antigenicity of the major $F$ and HN neutralization epitopes of the chimeric protein was preserved. Immunization of cotton rats with two 1 or $10 \mu \mathrm{g}$ doses of the chimeric protein adsorbed to aluminum phosphate elicited strong PIV-3 specific HAI responses as well as PIV-3 and RSV specific neutralizing antibodies, and at either dose completely protected against challenge with live RSV and PIV-3.

Received 14 December 1993; accepted 8 April 1994.

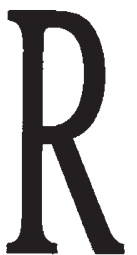

espiratory syncytial virus (RSV) and parainfluenza virus type 3 (PIV-3) cause severe respiratory tract infections in infants and young children ${ }^{1,2}$, and global mortality and morbidity figures ${ }^{3-5}$ indicate the need for developing safe and effective vaccines against these viral pathogens. Despite extensive research, such vaccines are not yet available. Neither formalininactivated PIV-3 and RSV vaccines ${ }^{6,7}$ nor live attenuated RSV vaccines $^{8,9}$ provided adequate protection in clinical trials. In fact, in some instances the formalin-inactivated RSV (FI-RSV) vaccines caused exacerbated disease following exposure to wildtype $\mathrm{RSV}^{6,7}$. It was orginally thought that an imbalance in the humoral immune response contributed to the observed potentiation of RSV disease. It was postulated that formalin-treatment of RSV altered important protective epitopes in the fusion (F) and attachment (G) surface glycoproteins of RSV resulting in an aberrant and largely non-functional antibody response which was responsible for pulmonary Arthus reactions during RSV infection 10. However, recent experimental evidence suggests that disease potentiation is not likely to be mediated by serum antibodies, but rather by a CD4 + T-cell mediated delayed-type hypersensitivity reaction ${ }^{11}$. The production of a single chimeric immunogen capable of protecting infants and young children against both PIV-3 and RSV infections, without causing augmented RSV disease, could result in a cost-effective vaccine that could significantly reduce the morbidity and mortality caused by these pathogens. A single dual-protective immunogen would have advantages over the production of individual proteins, including ease of production, purification and administration.

The proteins selected as target antigens for inclusion in the RSV/PIV-3 chimeric immunogen were the RSV fusion (F) and PIV-3 hemagglutinin-neuraminidase (HN) surface glycoproteins. The RSV F protein is highly conserved among RSV subgroups $\mathrm{A}$ and $\mathrm{B}$ and is a cross-protective antigen ${ }^{5.12}$. This viral protein is synthesized as a precursor (F0) molecule which is proteolytically cleaved to form a disulphide-linked dimer composed of the $\mathrm{N}$-terminal F2 and $\mathrm{C}$-terminal F1 moieties'. The PIV-3 HN attachment glycoprotein has been reported to play an important role in the induction of a protective immune response $^{2,13}$. The single recombinant RSV/PIV-3 immunogen was engineered to contain the RSV-F protein lacking the transmembrane domain and cytoplasmic tail linked to the hydrophilic ectodomain of the PIV-3 HN protein.

The baculovirus expression system was chosen to produce the chimeric immunogen since this expression system has been extensively used to produce a broad spectrum of recombinant proteins ${ }^{14}$ including viral surface and core antigens ${ }^{15}$. To date, Spodoptera frugiperda (Sf9) cells have been the cell line of choice for producing recombinant proteins with the baculovirus system. The individual PIV-3 and RSV surface glycoproteins ${ }^{16-18}$, hybrid RSV F-G ${ }^{19}$ and PIV-3 F-HN ${ }^{20}$ proteins as well as an $\mathrm{F}_{\mathrm{RSV}}-\mathrm{HN}_{\mathrm{PIV}-3{ }^{2}}{ }^{21}$ fusion protein engineered by Homa et al. ${ }^{21}$ have been produced in $\mathrm{Sf} 9$ cells using the baculovirus expression system. A new insect cell line (BT1-TN-5B1-4 or High Five ${ }^{\mathrm{TM}}$ ) derived from the cabbage looper, Trichoplasia ni is now available. These cells were reported to produce significantly higher levels of secreted glycoproteins than Sf9 cells $^{22}$. The use of High Five cells as an alternative to $\mathrm{S} f \mathrm{~g}$ cells to produce increased levels of a soluble and correctly processed form of a distinct $\mathrm{F}_{\mathrm{RSV}}-\mathrm{HN}_{\mathrm{PN}-3}$ protein was thus evaluated in this study. The immunoprotective properties of the chimera were also determined in order to assess the potential of using this recombinant protein as a candidate vaccine for protecting infants and young children against infections with RSV and PIV-3.

\section{Results}

Expression of the chimeric protein in insect cells. The primary sequence of the chimeric protein was designed to contain the first 526 amino acids of the RSV F protein linked in tandem to residues 54 to 573 of the PIV-3 HN protein. The presence of a soluble $\mathrm{F}_{\mathrm{RSV}}-\mathrm{HN}_{\mathrm{PIV} \text {-3 }}$ protein in the supernatants of baculovirus-infected $\mathrm{S} 9 \mathrm{9}$ and High Five cells (maintained in serum free medium EX401) was detected by Western blot analysis and the antigen-specific ELISAs. A distinct band with an $\mathbf{M}_{\mathrm{r}}$ of approximately $106 \mathrm{~K}$ was detected in the supernatants of both 
A

B
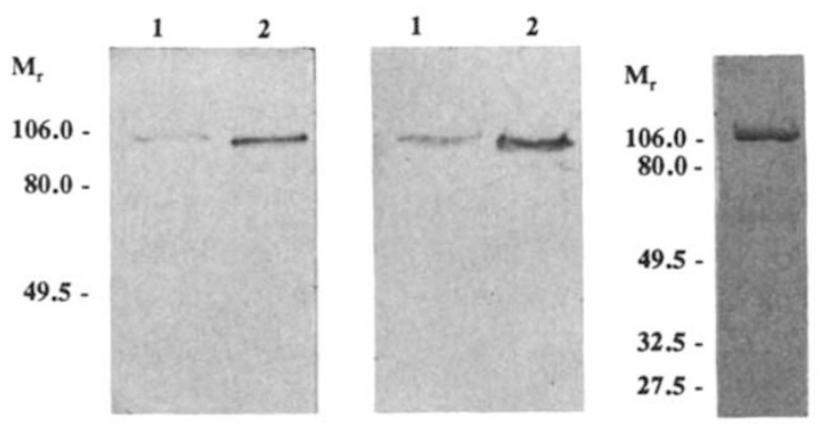

FIGURE 1. Panel A: Immunoblot of supernatants from infected Sf9 (Lane 1) and High Five (Lane 2) cells reacted with an anti-F MAb (5353C75). Panel B: Immunoblot of supernatants from infected Sf9 (Lane 1) and High Five (Lane 2) cells reacted with an anti-HN peptide antiserum. Each lane was loaded with an equivalent volume $(\mathbf{4 0} \mu \mathrm{l})$ of supernatant. Panel C: Coomassie blue-stained $10 \%$ SDS polyacrylamide gel of the immunoaffinity-purified $\mathbf{F}_{\mathrm{RSV}}-\mathrm{HN} \mathrm{NIV}_{\mathrm{PI}-3}$ protein electrophoresed under reducing conditions.

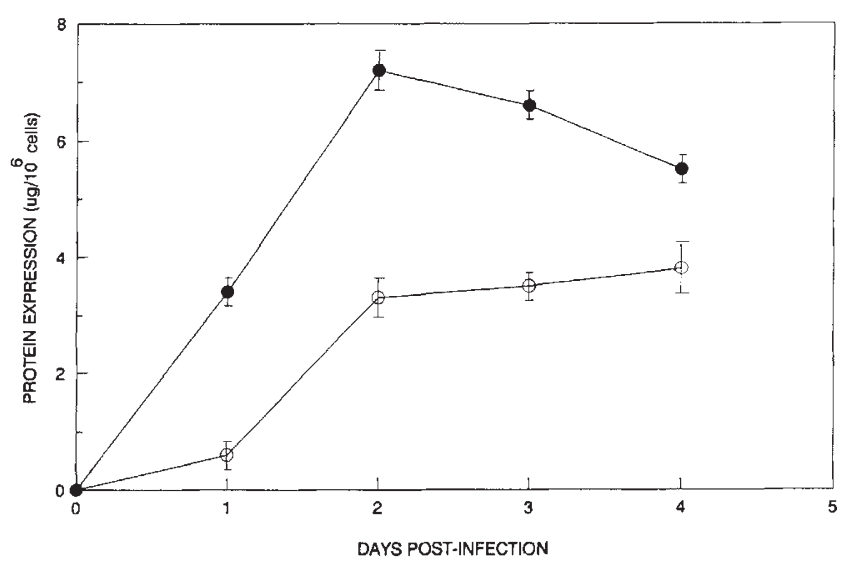

FIGURE 2. Time course of production of the soluble $F_{\text {RSV }^{-}}$ $H N_{\text {PIV-3 }}$ protein from infected Sf9 $(O)$ and High Five $(O)$ cells. At various times post-infection, the supernatant from infected cells was assayed for protein expression by the PIV-3 HN-specific ELISA. Each point represents the mean value of three independent determinations. The error bars represent the standard deviations.

Sf9 and High Five cells immunoblotted with the anti-F monoclonal antibody (MAb) 5353C75 (Fig. 1, Panel A) and an antiHN peptide antiserum (Fig. 1 Panel B). The supernatants also tested positive for protein expression in the RSV F and PIV-3 $\mathrm{HN}$ antigen-specific ELISAs. As expected, fluids from both uninfected and wild-type Autographa californica multiple nuclear polyhedrosis virus (AcMNPV)-infected cultures were negative in these assays.

The expression levels of the chimeric protein in the supernatants of infected Sf9 and High Five cells were compared at various times post-infection using the PIV-3 $\mathrm{HN}$-specific ELISA. As shown in Figure 2, the kinetics of chimera production was similar in both types of insect cells. The lowest level of protein was detected one day post-infection. A significant increase in the amount of $\mathrm{F}_{\mathrm{RSV}}-\mathrm{HN}_{\mathrm{PIV}-3}$ protein secreted into the medium was observed two days post-infection and remained relatively constant over the next 48 hours. High Five cells consistently produced more recombinant protein than $\mathrm{Sf} 9$ cells. At the optimal time of protein production ( 2 days post-infection) the average amounts of protein secreted from High Five and Sf9 cells were $21.6 \mu \mathrm{g} / 3 \times 10^{6}$ cells $/ \mathrm{ml}$ and $9.9 \mu \mathrm{g} / 3 \times 10^{6}$ cells $/ \mathrm{ml}$, respectively.

Purification of the $\mathrm{F}_{\mathrm{RSv}}-\mathrm{HN}_{\mathrm{PV}-3}$ chimeric protein. The soluble $\mathrm{F}_{\mathrm{RSV}}-\mathrm{HN}_{\mathrm{PIV}-3}$ protein was isolated from the supernatant of High Five cells 2 days post-infection since these conditions produced the highest antigen yields. The fusion protein was purified by immunoaffinity chromatography on an anti-HN MAb (PI65) column and was analyzed by SDS-PAGE under both reducing and non-reducing conditions. One major protein band with an $\mathrm{M}_{\mathrm{r}}$ of approximately $106 \mathrm{~K}$ (Fig. 1, Panel C) was detected in the reducing gels. This $\mathrm{M}_{\mathrm{r}}$ was compatible with that of a hypoglycosylated, processed form of the chimeric protein consisting of the truncated RSV F1 protein ( $\mathbf{M}_{r}$ approximately $47 \mathrm{~K}$ ) which has one potential oligosaccharide acceptor site ${ }^{1,23}$ linked to the truncated PIV-3 HN protein ( $M_{\text {r }}$ approximately $57 \mathrm{~K}$ ) which contains three potential sites for $\mathrm{N}$-glycosylation ${ }^{2,24}$. Edman degradation analysis of the protein extracted from the gel confirmed that the $\mathrm{F}_{\mathrm{RSV}}-\mathrm{HN}_{\mathrm{PIV}-3}$ protein was processed. The $\mathrm{N}$ terminal sequence (FLGFLLGVGSAIASGIAV) was found to correspond to residues 137 to 154 of the F protein. These residues are located immediately downstream from the natural proteolytic cleavage site situated between residues 136 and 137 (ref. 23). A band corresponding in $M_{r}$ to the hypoglycosylated F2 subunit (approximately 15K) was visible when the purified protein was run on a $12.5 \%$ reducing gel (data not shown). The purified protein reacted with both the anti-F MAb 5353C75 and the PIV-3 HN anti-peptide antiserum on immunoblots (data not shown).

Reactivity of the chimeric protein with anti-F and antiHN MAbs. The integrity of the major RSV F and PIV-3 HN neutralization epitopes in the chimeric protein was analyzed by testing its reactivity with a panel of anti-F and anti-HN MAbs. As shown in Table 1, both the chimeric protein and a recombinant RSV F (rF) protein (produced at the Connaught Centre for Biotechnology Research (CCBR)) reacted with MAbs (1153,

TABLE 1. Reactivity of anti-F and anti-HN monoclonal antibodies with the $\mathrm{F}_{\mathrm{RSV}}-\mathrm{HN}_{\mathrm{PIV}-3}, \mathrm{rF}$ and native $\mathrm{HN}$ proteins ${ }^{\mathrm{a}}$.

\begin{tabular}{|c|c|c|c|c|c|c|}
\hline MAb & $\begin{array}{l}\text { Antigenic } \\
\text { Site }^{\mathrm{b}}\end{array}$ & Epitope $^{b}$ & 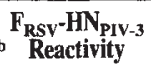 & $\begin{array}{c}\mathrm{rF} \\
\text { Reactivity }\end{array}$ & $\begin{array}{l}\text { Native HN } \\
\text { Reactivity }\end{array}$ & $\begin{array}{c}\text { BSA } \\
\text { Reactivit }\end{array}$ \\
\hline$\alpha-\operatorname{RSV} \mathbf{F}$ & & & & & & \\
\hline & $\begin{array}{l}\text { A } \\
\text { A }\end{array}$ & $\begin{array}{l}1 \\
3\end{array}$ & & & & $\overline{-}$ \\
\hline & B & 10 & & & & - \\
\hline 124 & $\mathrm{C}$ & 11 & 819,200 & 204,800 & N/A & - \\
\hline $5353 \mathrm{c} 75$ & $N / D^{c}$ & $N / D$ & $>3,276,800$ & $>3,276,800$ & $\mathrm{~N} / \mathrm{A}$ & - \\
\hline
\end{tabular}

$\alpha$-PIV-3

HN

$170 / 7$

$128 / 9$

$451 / 4$

$166 / 11$

$68 / 2$

$403 / 7$

PI65

A
A
A
A
B
C
N/D

$\begin{array}{cr}1 & 3,200 \\ 3 & 51,200 \\ 4 & 51,200 \\ 7 & 204,800 \\ 5 & 12,800 \\ 2 & 204,800 \\ \text { N/D } & >3,276,800\end{array}$

N/A

N/A $\quad 51,200$

N/A $\quad 51,200$

N/A $\quad 204,800$

N/A $\quad 819,200$

N/A $\quad 204,800$

N/A $\quad 819,200$

N/A $>3,276,800$

$\alpha$-HBsAg

458

aRelative reactivities (determined by an indirect ELISA) are expressed as the highest dilution of ascitic fluid which gave an $\mathrm{A}_{450}$ greater than the conjucate background $\mathrm{A}_{450}$ plus 2 times the standard deviations. Non-reactive titres are indicated by -.

${ }^{\mathrm{D} T h e}$ assignment of the anti-F and anti-HN MAbs to specific antigenic sites and epitopes are described by Wathen et al. ${ }^{25}$ and van Wyke Coeling et al. ${ }^{26}$, respectively.

cN/D-Not determined.

dN/A-Not applicable. 
A
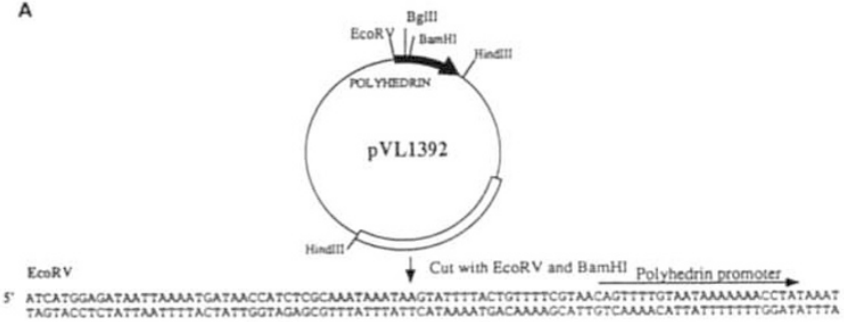

$$
1 \text { - } 6 \text { Ecokt }
$$

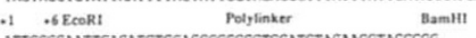

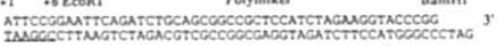

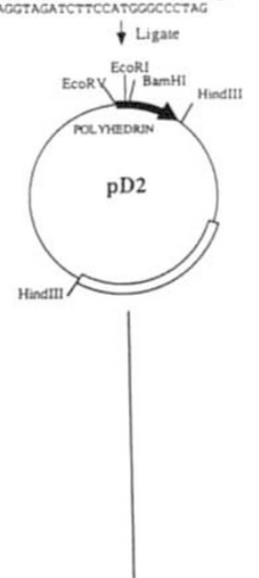

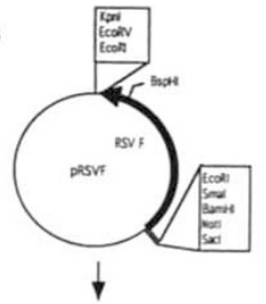

Cut with BspHI and EcoR!

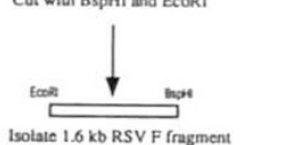

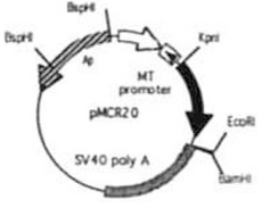

Deletion of BspHI sites

$\downarrow$

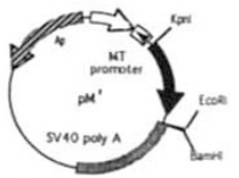

Cut with EcoRI and BamHI

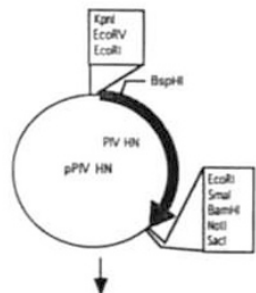

Cut with BspHI and BamHI
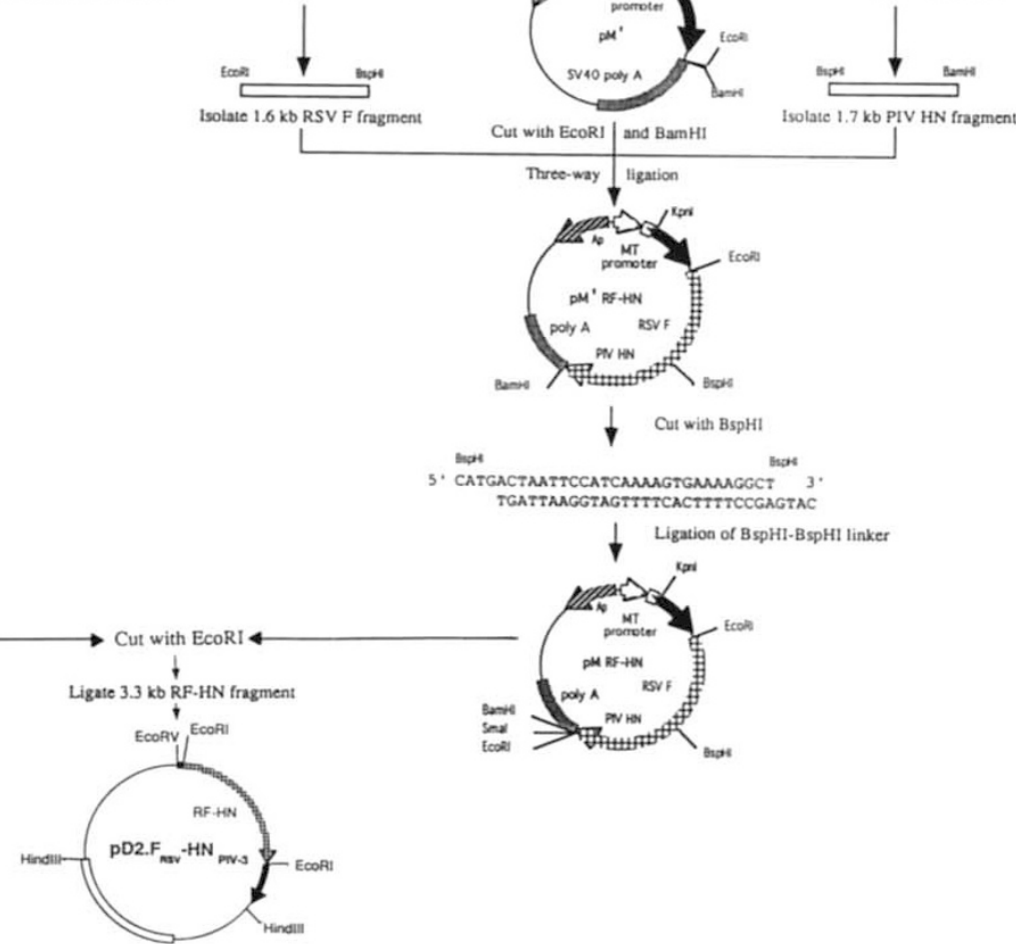

$\downarrow$ Cut with BspHI

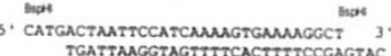

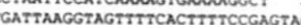

1 Ligation of BspHI-BspHI linker

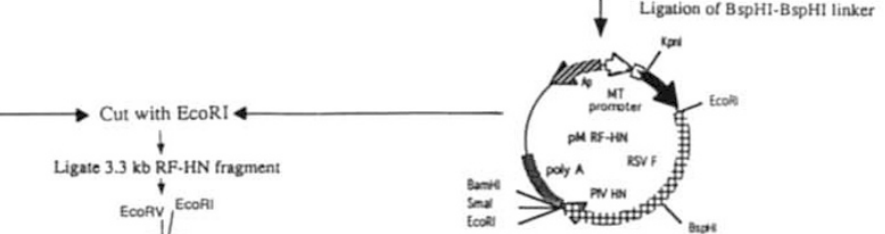

FIGURE 3. Panel A: Construction of the pD2 baculovirus transfer vector. The steps involved in modifying the baculovirus transfer vector, pVL1392, to produce the pD2 vector are outlined. Panel B: Construction of the pD2 transfer vector containing the chimeric $F_{\mathrm{RSV}^{-}} \mathrm{HN}_{\mathrm{PIV} \cdot 3}$ gene. The steps involved in constructing the modified mammalian expression vector, $\mathbf{p M}^{\prime}$, containing the truncated RSV F and PIV-3 genes linked in tandem and subcloning the FRSV-HNPIV-3 gene into the pD2 transfer vector are outlined.
$1237,1269,1243)$ directed against specific epitopes localized within the major antigenic sites (A,B and C) of the F protein ${ }^{25}$. The chimera and the $\mathrm{rF}$ protein also reacted strongly with the neutralizing MAb 5353C75. Both the $\mathrm{F}_{\mathrm{RSV}}-\mathrm{HN}_{\mathrm{PIV}-3}$ protein and native $\mathrm{HN}$ protein (prepared at $\mathrm{CCBR}$ according to the procedure outlined in the Experimental Protocol) reacted, to varying degrees, with anti-HN MAbs specific for 6 different epitopes located within antigenic sites $\mathrm{A}, \mathrm{B}$ and $\mathrm{C}^{26}$ of the $\mathrm{HN}$ protein. The chimera and the native $\mathrm{HN}$ protein reacted strongly with PI65, a MAb with high neutralizing activity against several PIV-3 isolates.

Immunogenicity and protective ability of the $\mathbf{F}_{\mathrm{RSv}}-\mathbf{H N}_{\mathrm{PIV}-3}$ protein. The immunogenicity of the chimeric protein was assessed in cotton rats. Significant PIV-3 specific-HAI as well as RSV and PIV-3 neutralizing antibody titres were observed in sera obtained 4 weeks after a single immunization of cotton rats with 1 or $10 \mu \mathrm{g}$ of the chimeric protein (Table 2). Both the PIV-3 specific HAI and PIV-3/RSV-neutralizing antibody titres were equivalent to those obtained by intranasal instillation of live PIV3 and RSV. Stronger neutralizing anti-PIV-3 and anti-RSV antibody titres were obtained following the booster dose ( 5 week bleed). Similar results were obtained in guinea pigs immunized with equivalent doses of the chimeric protein (data not shown).
The ability of the chimeric immunogen to confer dual protection against both viruses was determined by challenging cotton rats intranasally with 100 cotton rat infectious dose ${ }_{50}\left(\mathrm{CRID}_{50}\right)$ of either PIV-3 or RSV. The lungs of animals (Table 2 ) immunized with two 1 or $10 \mu \mathrm{g}$ doses of the $\mathrm{F}_{\mathrm{RSV}}-\mathrm{HN}_{\mathrm{PrV}-3}$ protein were completely protected against challenge with either PIV-3 or RSV. This protection was comparable to that elicited by intranasal immunization with either live PIV-3 or RSV.

\section{Discussion}

The primary objective of this study was to engineer a chimeric $\mathrm{F}_{\mathrm{RSV}}-\mathrm{HN}_{\mathrm{PrV}-3}$ protein which could be produced in sufficient yields to warrant its possible use as a prototype vaccine for protecting individuals against infections with both PIV-3 and RSV. To meet this objective, a soluble form of the chimera was engineered to facilitate purification of the recombinant protein. By designing the chimeric gene to contain the RSV F gene lacking the nucleotide sequences encoding the $3^{\prime}$ transmembrane anchor domain and cytoplasmic tail placed upstream of the HN gene devoid of the $5^{\prime}$ hydrophobic anchor domain, its product was expressed as a soluble protein from infected insect cells. The recent availability of new insect cell lines capable of secreting high levels of biologically active glycosylated ${ }^{22}$ pro- 
teins made the baculovirus expression system the method of choice for producing the chimera. It was reported that the levels of secreted glycosylated proteins such as alkaline phosphatase ${ }^{27}$ and the Epstein-Barr virus attachment protein gp 105 (ref. 28) were significantly greater in High Five cells than in Sf9 cells. At the optimal time of harvest ( 2 days post-infection), the yield of the $\mathrm{F}_{\mathrm{RSV}}-\mathrm{HN}_{\mathrm{PIV}-3}$ protein was consistently 2 -fold higher in High Five cells than in $\mathrm{S} f 9$ cells. High Five cells also have distinct advantages for scaling up production of the chimeric protein. These cells can be grown on microcarrier beads ${ }^{28}$ thereby providing a convenient means of propagating them in large fermentors. High Five cells have also been adapted to grow in the absence of serum. This not only reduces the cost of large scale production of the cells but also eliminates contaminating serum proteins which usually complicate the purification process.

The biochemical and immunological properties of the $F_{\mathrm{RSV}^{-}}$ $\mathrm{HN}_{\mathrm{PIV}-3}$ protein produced in High Five cells were assessed to ensure that the post-translational modifications required to produce biologically-active proteins were carried out by the cells. One such post-translational modification is the processing of the protein by endogenous proteases. $\mathrm{N}$-terminal sequence analysis of the purified $\mathrm{F}_{\mathrm{RSV}}-\mathrm{HN}_{\mathrm{PIV}-3}$ protein from High Five cells confirmed that the $\mathrm{F}$ component of the chimera was correctly processed at the primary F2-F1 cleavage site. The chimeric protein appears to have folded in such a manner that its $F$ component was cleaved by the specific endogenous protease at the authentic F2-F1 cleavage site. This mimicked the proteolytic processing pattern of the native RSV F protein'. In contrast, a smaller chimeric protein engineered by Homa et al. ${ }^{21}$ to contain the first 488 amino acids of the RSV F protein linked to amino acids 87 to 573 of the PIV-3 HN protein yielded a predominantely unprocessed molecule in Sf9 cells which tended either to aggregate during purification or be cleaved at a secondary proteolytic site within the $F$ portion of the chimera. This smaller chimeric protein may have a conformation which rendered its natural F-cleavage site less accessible to the specific endogenous protease. There is no data to indicate whether this abnormal processing affected the immunogenicity of certain neutralizing epitopes.

It was important to ensure that the antigenicity of the major $\mathrm{F}$ and $\mathrm{HN}$ neutralization epitopes of the chimeric protein produced in High Five cells was maintained. Potential misfolding of the $F$ and HN components of the chimera could affect the integrity of important neutralization determinants. To test its antigenicity, the $\mathrm{F}_{\mathrm{RSV}}-\mathrm{HN}_{\mathrm{prV}-3}$ protein was reacted with a panel of anti-F and anti-HN MAbs directed against the predominant antigenic sites of both glycoproteins. The chimeric protein reacted with the neutralizing anti-HN MAb PI65, as well as MAbs directed against neutralizing epitopes located within three antigenic sites $(\mathrm{A}, \mathrm{B}, \mathrm{C})$ of the $\mathrm{HN}$ molecule ${ }^{26}$. In particular, the integrity of the antigenic site $A$, reported to be one of the most important immunogenic sites of the HN protein ${ }^{29}$ was preserved. Similar results were obtained with the panel of anti-F MAbs. The $\mathrm{F}_{\mathrm{RSV}^{-}}$ $\mathrm{HN}_{\text {PIV-3 }}$ reacted with a neutralizing MAb $5353 \mathrm{C} 75$ as well as with MAbs specific for the $\mathrm{F}$ antigenic sites $\mathrm{A}, \mathrm{B}$, and $\mathrm{C}^{25}$.

The ability of the chimeric protein to elicit RSV/PIV-3 specific neutralizing antibodies and protect immunized animals against both PIV-3 and RSV infections had to be established before large scale production of the chimera could be considered. Two $1 \mu \mathrm{g}$ doses of the chimeric protein protected immunized cotton rats against infection with both PIV-3 and RSV. The immunoprotective ability of the $\mathrm{F}_{\mathrm{RSV}}-\mathrm{HN}_{\mathrm{PIV}-3}$ protein produced in High Five cells was similar to that of an immunoaffinitypurified RSV F enriched protein preparation obtained from the lysates of RSV infected HEp- 2 cells ${ }^{30}$. In addition, the ability of the chimeric protein to protect against PIV-3 infection was comparable to that of a mixture of PIV3 $\mathrm{HN}+\mathrm{F}$ antigens copurified from detergent-solubilized virus by lentil-lectin affinity chromatography ${ }^{31}$.

It was reported that proteins produced in insect cells normally contain only high-mannose residues in contrast to the complex oligosaccharides present in mammalian cell-derived proteins ${ }^{32}$. Although the $\mathrm{F}_{\mathrm{RSV}}-\mathrm{HN}_{\mathrm{PIV}-3}$ protein produced in High Five cells was hypoglycosylated, this did not affect its ability to react with neutralizing anti-HN and anti-F MAbs or to elicit a protective immune response in cotton rats. Similar observations were made with respect to the immunoprotective abilities of recombinant RSV F ${ }^{18}, \mathrm{PIV}-3$ (ref. 20) HN or the hybrid RSV $\mathrm{FG}^{19}$, PIV-3 FHN ${ }^{20}, \mathrm{~F}_{\mathrm{RSV}}-\mathrm{HN}_{\mathrm{PIV}-3}{ }^{21}$ proteins produced in Sf9 cells. These results suggest that the glycosylation patterns of the native $\mathrm{F}$ and $\mathrm{HN}$ proteins do not necessarily have to be preserved to maintain the proper folding of their protective epitopes.

Before clinical testing is initiated with the $\mathrm{F}_{\mathrm{RSV}}-\mathrm{HN}_{\mathrm{PIV}-3}$ protein described herein, it will be important to ensure that this chimera does not cause enhanced pulmonary pathology in immunized cotton rats ${ }^{33}$ and African green monkeys ${ }^{34}$ following live virus challenge. In this study, animals injected with formalin-inactivated RSV will serve as positive controls for demonstrating increased pulmonary pathology in immunized animals following RSV challenge while animals immunized with live virus will serve as negative controls.

In summary, we have demonstrated the feasibility of producing a soluble and correctly processed form of the genetically engineered $\mathrm{F}_{\mathrm{RSV}}-\mathrm{HN}_{\mathrm{PIV}-3}$ protein in High Five cells using the

TABLE 2. Immunoprotective ability of the $\mathrm{F}_{\mathrm{RSV}}-\mathrm{HN}_{\mathrm{PIV}-3}$ protein in cotton rats.

\begin{tabular}{|c|c|c|c|c|c|c|c|c|c|}
\hline \multirow{3}{*}{$\begin{array}{l}\text { Antigen } \\
\text { Formulation }\end{array}$} & \multirow{3}{*}{$\begin{array}{l}\text { Dose } \\
(\mu \mathrm{g})\end{array}$} & \multirow{2}{*}{\multicolumn{2}{|c|}{$\begin{array}{c}\text { HAI Titrea,b } \\
\left(\log _{2} \pm S D\right) \\
\text { PIV-3 }\end{array}$}} & \multirow{2}{*}{\multicolumn{4}{|c|}{$\begin{array}{c}\text { Neutralization Titre }{ }^{\mathrm{u}, \mathrm{c}} \\
\left(\log _{2} \pm \text { SD }\right)\end{array}$}} & \multicolumn{2}{|c|}{$\begin{array}{l}\text { Mean Virus Lung Titre } \\
\left(\log _{10} / g \text { lung } \pm \mathrm{SD}\right)^{\mathrm{d}}\end{array}$} \\
\hline & & & & & & & & & \\
\hline & & 4 wk Bleed & 5 wk Bleed & 4 wk Bleed & 5 wk Bleed & 4 wk Bleed & 5 wk Bleed & & \\
\hline Buffer & - & $2.8 \pm 0.5$ & $<3.0 \pm 0.0$ & $<1.0 \pm 1.0$ & $1.8 \pm 1.1$ & $1.8 \pm 0.3$ & $0.8 \pm 0.7$ & $3.4 \pm 0.3$ & $3.7 \pm 0.3$ \\
\hline $\mathrm{F}_{\mathrm{RSV}}-\mathrm{HN}_{\mathrm{PIV}-3}$ & $\begin{array}{r}10.0 \\
1.0\end{array}$ & $\begin{array}{l}9.5 \pm 1.3 \\
9.3 \pm 1.0\end{array}$ & $\begin{array}{l}10.5 \pm 0.6 \\
10.3 \pm 0.5\end{array}$ & $\begin{array}{l}9.5 \pm 0.0 \\
8.9 \pm 0.5\end{array}$ & $\begin{array}{l}10.9 \pm 0.5 \\
10.9 \pm 0.9\end{array}$ & $\begin{array}{l}5.2 \pm 1.1 \\
5.0 \pm 0.7\end{array}$ & $\begin{array}{l}5.8 \pm 0.9 \\
5.8 \pm 1.2\end{array}$ & $\begin{array}{l}\leq 1.5 \pm 0.0 \\
\leq 1.5 \pm 0.0\end{array}$ & $\begin{array}{l}\leq 1.5 \pm 0.0 \\
\leq 1.5 \pm 0.0\end{array}$ \\
\hline Live PIV-3 & $\begin{array}{ll}100 \\
\text { CRID }_{50}\end{array}$ & $7.0 \pm 0.0$ & $8.5 \pm 0.7$ & $9.2 \pm 0.7$ & $>9.0 \pm 0.0$ & N/A & N/A & $\leq 1.5 \pm 0.0$ & N/A \\
\hline Live PIV-3 & $\begin{array}{l}100 \\
\text { CRID }_{50}\end{array}$ & $N / A^{e}$ & N/A & N/A & N/A & $5.5 \pm 0.6$ & $8.5 \pm 0.6$ & N/A & $\leq 1.5 \pm 0.0$ \\
\hline
\end{tabular}

aEach value represents the mean titre of antisera from 8 animals.

'Reciprocal mean $\log _{2}$ serum dilution which inhibits erythrocyte agglutination by 4 hemagglutinating units of PIV-3.

${ }^{c}$ Reciprocal mean $\log _{2}$ serum dilution which blocks hemadsorption/cytopathic effect of 100 TCID 50 units of either PIV-3 or RSV.

dAnimals were challenged intranasally with 100 CRID $_{50}$ of either PIV-3 or RSV and killed 4 days later. Each value represents the mean titre of 4 animals.

eN/A-not applicable. 
baculovirus expression system. Production of this immunogenic and dual protective chimera may provide an alternate strategy for controlling the severe respiratory tract infections caused by PIV-3 and RSV.

\section{Experimental Protocol}

Cells and viruses. Sf 9 and High Five insect cells were obtained from BDH Inc. (Toronto, Ont.) and Invitrogen (San Diego, CA), respectively. Sf9 cells were grown in Hank's TN2M-FH insect cell medium (JRH Biosciences, Lenexa, KS) containing 10\% fetal calf serum (Hazelton, Lenexa, KS) while High Five cells were grown in Ex-Cell 401 serum-free medium (JRH Biosciences, Lenexa, KS). For expression studies, Sf9 and High Five cells were maintained in Ex-Cell 401 serum-free medium. MRC-5 cells were obtained from the Cell Services department of Connaught Laboratories Ltd. The PIV-3 clinical isolate (PIV-3 ${ }_{\text {Toronto }}$ ) was obtained from the Public Health Laboratory (Toronto, Ont.) while the RSV type $A$ isolate $\left(\mathbf{R S V}_{\text {Trac }}\right.$ ) was obtained from Baylor College of Medicine (Houston, TX). Wild type AcMNPV was purchased from Invitrogen (San Diego, CA)

Cloning and sequencing the RSV F and PIV-3 HN genes. The human RSV F and PIV-3 HN genes were cloned from cDNA libraries prepared from mRNA isolated from MRC-5 cells infected with clinical isolates of either PIV- $3_{\text {Toron }}$ or RSV type $\mathrm{A}_{\text {Tracy }}$. The full-length RSV F and PIV-3 HN genes were cloned into phage $\lambda$ gtll and subcloned into the EcoRI site of a Bluescript M13-SK vector. The vectors containing the RSV $\mathrm{F}$ and PIV-3 HN genes were designated pRSVF and pPIVHN, respectively. Both strands of two RSV F and two PIV-3 HN gene clones were sequenced by the dideoxynucleotide chain termination procedure ${ }^{35}$. The complete nucleotide sequence of the PIV-3 $\mathrm{HN}_{\text {Torunto }}$ and RSV-F $\mathrm{F}_{\text {Tracy }}$ genes were deposited in both GenBank (accession numbers L25350 (HN gene) and L25351 (F gene)) and the EMBL data library (accession numbers $\mathrm{Z} 26523$ (HN gene) and Z26524 (F gene)).

Construction of the pD2 baculovirus transfer vector. The baculovirus transfer vector pVL1392 (Invitrogen, San Diego, CA.) was modified according to the steps outlined in Figure 3A. After cutting the pVL 1392 vector with EcoRV and BamHI, the $9.5 \mathrm{~kb}$ restricted pVL1392 vector was ligated to an EcoRV-BamHI oligonucleotide cassette to produce the new transfer vector designated, pD2.

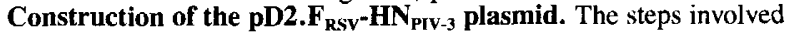
in constructing the $\mathrm{pD} 2$ transfer vector containing the truncated RSV F and PIV-3 HN genes linked in tandem are summarized in Figure 3B. The RSV F gene lacking the nucleotide sequence coding for the transmembrane domain and cytoplasmic tail of the $\mathrm{F}$ glycoprotein was retrieved from plasmid pRSVF by cutting the gene with $\mathrm{BspHI}$ and the polylinker with EcoRI. The PIV-3 HN gene devoid of the DNA segment encoding the hydrophobic anchor domain was retrieved from plasmid pPIVHN by cutting the gene with BspHI and the polylinker with BamHI. The $1.6 \mathrm{~Kb}$ EcoRI-BspHI RSV F and the $1.7 \mathrm{~Kb}$ BspHI-BamHI PIV-3 HN gene fragments were isolated from low melting point agarose gels. For cloning purposes, the two BspHI sites in the Bluescript-based mammalian cell expression vector, pMCR20, were mutated. Mutations were introduced in the BspHI sites of pMCR20 by cutting the vector with BspHI, bluntending the BspHI restricted vector with Klenow polymerase and religating the blunt-ended vector to generate plasmid $\mathrm{pM}^{\prime}$. The $1.6 \mathrm{~Kb}$ EcoRI-BspHI RSV F and 1.7 Kb BspHI-BamHI PIV-3 HN gene fragments were directly cloned into the EcoRI-BamHI sites of vector $\mathrm{pM}^{\prime}$ in a 3-way ligation to generate plasmid $\mathrm{PM}^{\prime} \mathrm{RF}-\mathrm{HN}$. The coding sequences of the RSV F and PIV-3 HN genes removed by the BspHI cut were restored by insertion of a BspHI-BspHI oligonucleotide cassette to produce plasmid pM RF-HN. Clones containing the BspHI-BspHI cassette in the proper orientation were identified by DNA sequence analysis of the oligonucleotide linker and its flanking regions. To clone the $\mathrm{F}_{\mathrm{RSV}}-\mathrm{HN}_{\mathrm{PIV}-3}$ gene into the $\mathrm{pD} 2$ transfer vector, the truncated chimeric gene was first retrieved from plasmid pM RF-HN by digestion with EcoRI. The $3.3 \mathrm{~Kb}$ $\mathrm{F}_{\mathrm{RSV}}-\mathrm{HN}_{\mathrm{PIV}-3}$ chimeric gene was then cloned into the EcoRI site of plasmid $\mathrm{pD} 2$ to generate plasmid $\mathrm{pD} 2 . \mathrm{F}_{\mathrm{RSV}}-\mathrm{HN}_{\mathrm{PIV}-3}$. Proper orientation of the 3.3 Kb EcoRI $\mathrm{F}_{\mathrm{RSV}}-\mathrm{HN} \mathrm{N}_{\mathrm{PIV}-3}$ gene insert in plasmid $\mathrm{pD} 2 . \mathrm{F}_{\mathrm{RSV}}-\mathrm{HN} \mathrm{N}_{\mathrm{PIV}-3}$ was confirmed by restriction mapping and DNA sequence analysis.

Preparation of recombinant baculoviruses containing the $\mathbf{F}_{\mathrm{RSV}}-$ HN $_{\text {PIV-3 }}$ gene. Sf9 cells were co-transfected with $1 \mu \mathrm{g}$ wild-type AcMNPV DNA (Invitrogen, San Diego, CA) and $2 \mu \mathrm{g}$ of pD2. $\mathrm{F}_{\mathrm{RSv}}-\mathrm{HN} \mathrm{N}_{\mathrm{PIV}-3}$ plasmid DNA. Putative recombinant baculoviruses containing the $\mathrm{F}_{\mathrm{RSV}}-\mathrm{HN}_{\mathrm{PIV}-3}$ gene were identified by dot-blot hybridization. Lysates of infected insect cells were screened with ${ }^{32}$ P-labelled RSV F and PIV-3 HN gene-specific probes. Recombinant baculoviruses were plaque-purified three times before being used for expression studies. All procedures were carried out according to the protocols outlined by Summers and Smith ${ }^{36}$.

Monoclonal antibodies and antisera. Panels of anti-F and anti-HN MAbs were kindly provided by J. Beeler (NIAID, Bethesda, MD., in accordance with the $\mathrm{WHO} /$ programme for vaccine development). The anti-F and anti-HN MAbs were prepared at the National Institute of Health (NIH, Bethesda MD) by the procedures cited by Wathen et al. ${ }^{25}$ and van Wyke Coelingh et al. ${ }^{26}$, respectively. The anti-F MAb (5353C75) was obtained from J-M. Chapsal (Institut Mérieux, Lyon, France). The antiHN hybridoma (PI65) cell line was produced by conventional techniques using BALB/c mice immunized with PIV-3 glycoproteins co-purified from detergent-treated virus by lentil lectin affinity chromatography ${ }^{37}$ Spleen cells from hyperimmune mice were then fused to the myeloma cell line X63. The guinea pig anti-RSV antiserum was obtained from the NIH (Bethesda, MD.) The anti-PIV-3 antiserum was prepared by immunizing guinea pigs with detergent-treated, sucrose gradient-purified PIV-3 emulsified in Freund's adjuvant. To prepare the anti-HN peptide antiserum, guinea pigs were immunized with 3 doses of a mixture containing $100 \mu \mathrm{g}$ of each peptide emulsified in Freund's complete and incomplete adjuvant. The peptides corresponded to the sequences of predicted linear T-B tandem epitopes of the HA-1 (ref. 38) strain (residues 94 to 112; 184 to 206 209 to $230 ; 234$ to $256 ; 261$ to $293 ; 323$ to 350 and 372 to 396 ). Sera were collected 10 days after the final booster dose.

RSV F and PIV-3 HN antigen ELISAs. The chimeric $\mathrm{F}_{\mathrm{RSV}}-\mathrm{HN}_{\mathrm{PIV}-3}$ protein was quantitated in conventional indirect ELISAs specific for the RSV F and PIV-3 HN proteins. In the RSV F specific ELISA, plates were coated with guinea pig anti-RSV $\operatorname{lgG}$ antibody purified from a reference antiserum obtained from the NIH. The secondary antibody was the anti-F $\mathrm{MAb}$ 5353C75. Immunoaffinity-purified recombinant RSV F protein produced at CCBR, was used as a standard. In the indirect PIV-3 HN ELISA, microtitre plates were coated with purified guinea pig anti-PIV-3 IgG. Purified anti-HN MAb PI65 was used as the second antibody. The $\mathrm{HN}$ protein standard was purified from a PIV-3 glycoprotein-enriched preparation by gel filtration chromatography followed by negative selection on an anti-F immunoaffinity column. In both assays, wells were incubated with anti-mouse IgG conjugated to horseradish peroxidase (Jackson Labs, West Grove, PA) followed by incubations with the substrate tetramethylbenzidine (TMB) $/ \mathrm{H}_{2} \mathrm{O}_{2}$. After terminating the reactions with $4 \mathrm{M} \mathrm{H}_{2} \mathrm{SO}_{4}$, the absorbance was measured at $450 \mathrm{~nm}$ (using $540 \mathrm{~nm}$ as a reference wavelength). Samples were tested in triplicate. Culture supernatants from wild-type virus infected, and non-infected cells were used as negative controls.

Expression of the chimeric $\mathrm{F}_{\mathrm{RSV}}-\mathrm{HN}_{\mathrm{PIV}-3}$ protein in Sf9 and High Five cells. Sf9 and High Five cells, maintained in serum free medium EX401, were infected with the plaque-purified recombinant baculoviruses at a multiplicity of infection (m.o.i) of 5 PFU/cell. Supernatants from infected cells were harvested at days $1,2,3$ and 4 post-infection and analyzed for protein expression in both the RSV F and PIV-3 HN specific ELISAs. Culture supernatants from wild-type virus infected and noninfected cells served as negative controls.

SDS-PAGE and Western blot analyses. Proteins were analyzed by SDS-PAGE using $7.5 \%, 10 \%$ and $12.5 \%$ polyacrylamide gels under reducing and non-reducing conditions according to Laemmli ${ }^{39}$. Protein bands were visualized by Rapid Coomassie blue staining (Diversified Biotech, Newton Centre, MA). For Western blot analysis, proteins were electrophoretically transferred from $10 \%$ SDS gels run under reducing conditions to polyvinyldifluoride (PVDF) membranes. After blocking with $5 \%$ Blotto, membranes were probed with an appropriate dilution of either the anti-RSV F MAb (5353C75) or the anti-HN peptide antiserum. Depending on the probing antibody used, protein bands were reacted with either a goat anti-mouse or goat anti-guinea pig IgG antibody conjugated to alkaline-phosphatase and visualized by the 5-bromo-4-chloro-3-indoyl phosphate $p$-toluidine salt (BCIP) and $p$-nitro blue tetrazolium chloride (NBT) color development system prepared according to the manufacturer's instructions (Biorad, Hercules, CA).

Purification of the chimeric $\mathrm{F}_{\mathrm{Rs}}-\mathrm{HN}_{\mathrm{PIV}-3}$ protein from the supernatant of infected High Five cells. High Five cells, maintained in serum free medium EX401, were infected with the plaque-purified recombinant baculoviruses at an m.o.i. of $5 \mathrm{PFU} /$ cell. The supernatant from virusinfected cells was harvested 2 days post-infection. To prevent possible proteolytic degradation of the expressed protein, a cocktail of protease inhibitors (1 $\mathrm{mM}$ aminoethyl-benzenesulfonylfluoride (AEBSF), $2 \mathrm{mM}$ EDTA, $1 \mu \mathrm{M}$ pepstatin and $1 \mu \mathrm{M}$ leupeptin) was added to the supernatant The soluble $\mathrm{F}_{\mathrm{RSV}}-\mathrm{HN}_{\mathrm{PIV}-3}$ chimera was purified from this supernatant by immunoaffinity chromatography on an anti-HN MAb (PI65)-Sepharose $4 \mathrm{~B}$ column. The FRSV-HNPIV-3 protein was eluted with $100 \mathrm{mM}$ glycine$\mathrm{HCl}, \mathrm{pH} 2.5$, in the presence of $0.02 \%$ Triton X-100 and immediately neutralized with $1 \mathrm{M}$ Tris base.

$\mathrm{N}$-terminal sequence analysis. The immunoaffinity purified $\mathrm{F}_{\mathrm{RSV}}$ $\mathrm{HN}_{\mathrm{PIV}-3}$ protein was run on a $10 \% \mathrm{SDS}$ polyacrylamide gel under reducing conditions and electrophoretically transferred to PVDF membranes. The protein with an apparent $M_{r}$ of $106 \mathrm{~K}$ was extracted from the gel and subjected to $\mathrm{N}$-terminal sequence analysis using an $\mathrm{ABI} 477 \mathrm{~A}$ protein sequencer $/ 120$ analyzer.

Antigenicity of the $\mathbf{F}_{\mathrm{RSV}}-\mathrm{HN}_{\mathrm{PIV} \cdot 3}$ protein. The reactivity of the immunoaffinity-purified chimeric protein with a panel of anti- $F$ and antiHN MAbs was determined by indirect ELISAs. Nunc-MaxiSorp ELISA plate wells were coated overnight with $50 \mathrm{ng}$ of either purified PIV-3 HN recombinant RSV F, or $\mathrm{F}_{\mathrm{RSV}}-\mathrm{H} \mathrm{N}_{\mathrm{PSV}-3}$ protein diluted in $0.05 \mathrm{M}$ carbonate buffer, $\mathrm{pH}$ 9.5. The wells were washed with phosphate buffered saline (PBS) containing $0.1 \%(\mathrm{w} / \mathrm{v})$ bovine serum albumin (BSA) and $0.1 \%$ (v/v) Tween 20 and blocked with PBS containing $0.1 \% \mathrm{w} / \mathrm{v}$ BSA. Starting with an initial dilution of $1 / 200$, the ascitic fluids were serially diluted four-fold in wash buffer ( $150 \mu \mathrm{l} /$ well) and were incubated for one hour at room temperature. After washing, bound MAbs were reached with a peroxidase-labelled anti-mouse IgG (Jackson Labs, West Grove, PA) antibody diluted $1: 30,000$. Peroxidase activity was determined by adding $100 \mu \mathrm{l} \mathrm{TMB} / \mathrm{H}_{2} \mathrm{O}_{2}$ as substrate. The relative reactivity of each of the MAbs 
was determined as the reciprocal of the highest ascitic fluid dilution which gave an $\mathrm{A}_{450}$ greater than the conjugate background $\mathrm{A}_{450}$ plus 2 times the standard deviation. Non-reactive titres were indicated by -. MAb 458 directed against the Hepatitis B virus surface antigen (HBsAg) was used as the negative control. Each MAb was tested for non-specific binding to BSA-coated wells. The anti-F MAb 5353C75 and anti-HN PI65 were used as positive controls in each of the ELISAs. The reactivity of each MAb was tested in triplicate.

Virological and serological assays. Tissue culture infectious dose ${ }_{50}$ $\left(\mathrm{TCID}_{50}\right)$, haemagglutination inhibition (HAI), and neutralization titre were determined by standard assay procedures ${ }^{31.40}$. Antibody titers were expressed as the reciprocal mean $\log _{2}$ of the highest dilution of serum which completely blocked haemagglutination or virus infectivity.

Protein determination. Protein concentrations were determined by the micro bicinchoninic acid (BCA) assay (Pierce, Rockford, MA) according to the manufacturer's instructions.

Immunogenicity and protective ability of $\mathrm{F}_{\mathrm{RSv}}-\mathrm{HN}_{\mathrm{PrV}-3}$ protein in cotton rats. Groups of eight cotton rats (Sigmoden hispidus, male and female, $50-100 \mathrm{~g}$ ) were injected intramuscularly with either 1.0 or $10.0 \mu \mathrm{g}$ of the $\mathrm{F}_{\mathrm{RSV}}-\mathrm{HN}_{\mathrm{PIV}-3}$ protein adjuvanted with $0.5 \mathrm{mg}$ aluminum phosphate. Groups of control animals were immunized with either placebo or live PIV-3 or RSV (100 CRID ${ }_{50}$ ), administered intranasally). Animals were bled 4 weeks after the primary injection and, except for animals that received live virus, were boosted with an equivalent dose of the antigen formulation. Serum samples were taken 1 week after the booster dose after which four cotton rats from each group were challenged intranasally with $100 \mathrm{CRID}_{50}$ of either PIV-3 or RSV. Animals were sacrificed 4 days later. Lungs were asceptically removed, weighed, and transpleurally lavaged with media supplemented with $5 \%$ fetal bovine serum as previously described ${ }^{31}$. The titres of infectious PIV-3 and RSV in lung lavages were determined in the TCID s $_{0}$ assay.

\section{Acknowledgments}

We are grateful to B. Bradley, D. England, P. Fan, M. Flood, D. McLeod, T. Phillips, N. Scollard, L. Urbanczyk and L. Xu for providing excellent technical assistance. This work was supported, in part by the Ontario Premier's Council Technology Fund. This investigation also received support from the WHO/UNDP programme for vaccine development.

\section{References}

1. McIntosh, K. and Chanock, R. M. 1990. Respiratory syncytial virus, p. 1045 1072. In: Virology. Fields, B. N. and Knipe, D. M. (Eds.). Raven Press, New York

2. Chanock, R. M. and McIntosh, K. 1990. Parainfluenza viruses, p. 963-988. In Virology. Fields, B. N. and Knipe, D. M. (Eds.). Raven Press, New York.

3. Katz, S. L. 1985. Prospects for immunizing against parainfluenza viruses p. 385-396. In: New Vaccine Development Establishing Priorities. Vol. 1, National Academic Press, Washington, D.C.

4. Katz, S. L. 1985. Prospects for immunizing against respiratory syncytial virus, p. 397-409. In: New Vaccine Development Establishing Priorities. Vol. 1, National Academic Press, Washington, D.C

5. Wertz, G. W. and Sullender, W. M. 1992. Approaches to immunization against respiratory syncytial virus. Biotechnology 20:151-176.

6. Fulginiti, V. A., Eller, J. J., Sieber, O. F., Joyner, J. W., Minamitani, M. and Meiklejohn, G. 1969. Respiratory virus immunization. I. A field trial of two inactivated respiratory virus vaccines: an aqueous trivalent parainfluenza virus vaccine and an alum-precipitated respiratory syncytial vinus vaccine. Am. J. Epidemiol. 89:449-463.

7. Chin, J., Magoffin, R. L., Shearer, I. A., Schieble, J. H. and Lennette, E. H. 1969. Field evaluation of a respiratory syncytial virus vaccine and a trivalent parainfluenza virus vaccine in a pediatric population. Am. J. Epid. 89:449-463.

8. Belshe, R. B., Van Voris, L. P. and Mufson, M. A. 1982. Parenteral administration of live respiratory syncytial virus vaccine: results of a field trial. J. Infect. Dis. 145:311-319.

9. Kim, H. W. Arrobio, J. O., Pyles, G., Brandt, C. D., Camargo, E., Chanock, R. M. and Parrott, R. H. 1971. Clinical and immunological response of infants and children to administration of low-temperature adapted respiratory syncytial virus. Pediatrics 48: 745-755.

10. Chanock, R. M., Parrott, R. H., Connors, M., Collins, P. L., and Murphy, B. R. 1992. Serious respiratory tract disease caused by respiratory syncytial virus prospects for improved therapy and effect immunization. Pediatrics 90:137-142.

11. Connors, M., Kulkarni, A. B., Firestone, C.-Y., Holmes, K. L., Morse, H., Sotnikov, A. V. and Murphy, B. R. 1992. Pulmonary histopathology induced by respiratory syncytial virus (RSV) challenge of formalin-inactivated RSV-immunized BALB/c mice is abrogated by depletion of $\mathrm{CD}^{+} \mathrm{T}$ cells. J. Virol. 66:7444-7451.

12. Olmsted, R. A., Elango, N. and Prince, G. A. 1991. Expression of the F glycoprotein of respiratory syncytial virus by a recombinant vaccinia virus: comparison of the individual contributions of the $\mathrm{F}$ and $\mathrm{G}$ glycoproteins to hos immunity. Proc. Natl. Acad. Sci. USA 83:7462-7466.

13. Spriggs, M. K., Murphy, B. R., Prince, G. A., Olmsted, R. A. and Collins, P. L. 1987. Expression of the $F$ and $H N$ glycoproteins of human parainfluenza virus type 3 by recombinant vaccinia viruses: contributions of the individual proteins to host immunity. J. Virol. 61:3416-3423.

14. Luckow, V. A. 1990. Cloning and expression of heterologous genes in insect cells with baculovirus vectors, p. 1-24. In: Recombinant DNA Technology and Applications. Ho, C., Prokop, A., Baipai, R. (Eds.). McGraw-Hill, New York.
15. King, L. A. and Possee, R. D. 1992. Processing of foreign proteins synthesized using baculovirus vectors in insect cells, p. 37-50. In: The Baculovirus Expression System. King, L. A. and Possee, R. D. (Eds.). Chapman and Hall, New York.

16. Lehman, D. J., Roof, L. L., Brideau, R. J., Aeed, P. A., Thomsen, D. R., Elhammer, A. P., Wathen, M. W. and Homa, F. L. 1993. Comparison of soluble and secreted forms of human parainfluenza virus type 3 glycoproteins expressed from mammalian and insect cells as subunit vaccines. J. Gen. Virol. 74:459-469

17. Ray, R., Galinski, M. S. and Compans, R. W. 1989. Expression of the fusion glycoprotein of human parainfluenza type 3 virus in insect cells by a recombinant baculovirus and analysis of its immunogenic property. Virus Res. 12: $169-190$.

18. Wathen, M. W., Brideau, R. J. and Thomsen, D. R. 1989. Immunization of cotton rats with the human respiratory syncytial virus $\mathrm{F}$ glycoprotein produced using a baculovirus vector. J. Infect. Dis. 159:255-264.

19. Brideau, R. J., Walters, R. R., Stier, M. A. and Wathen, M. W. 1989. Protection of cotton rats against human respiratory syncytial virus by vaccination with a novel chimeric FG glycoprotein. J. Gen. Virol. 70:2637-2644.

20. Brideau, R. J., Oien, N. L. Lehman, D. J. Homa, F. L. and Wathen, M. W 1993. Protection of cotton rats against human parainfluenza virus type 3 by vaccination with a chimeric FHN subunit glycoprotein. J. Gen. Virol. 74:471-477

21. Homa, F. L., Brideau, R. J., Lehman, D. J., Thomsen, D. R., Olmsted, R. A and Wathen, M. W. 1993. Development of a novel subunit vaccine that protect cotton rats against both human respiratory syncytial virus and human parainfluenza virus type 3. J. Gen. Virol. 74:1995-1999.

22. Wickman, T. J., Davis, T., Granados, R. R., Shuler, M. L. and Wood, H. A 1992. Screening of insect cell lines for the production of recombinant proteins and infectious virus in the baculovirus expression system. Biotechnol. Prog. 8:391-396

23. Collins, P. L., Huang, Y. T. and Wertz, G. W. 1984. Nucleotide sequence of the gene encoding the fusion (F) glycoprotein of human respiratory syncytial virus. Proc. Natl. Acad. Sci. USA 81:7683-7687.

24. Elango, N., Coligan, J. E., Jambou, R. C. and Venkatesan, S. 1986. Human parainfluenza type 3 virus hemagglutinin-neuraminidase glycoprotein:nucleotide sequence of mRNA and limited amino acid sequence of the purified protein. J. Virol. 57:481-489.

25. Wathen, M. W., Brideau, R. J., Thomsen, D. R. and Murphy, B. R. 1989 Characterization of a novel human respiratory syncytial virus chimeric FG glycoprotein expressed using a baculovirus vector. J. Gen. Virol 70:2625-2635.

26. van Wyke Coelingh, K. L., Winter, C. C., Jorgensen, E. D. and Murphy, B. R. 1987. Antigenic and structural properties of the hemagglutinin-neuraminidase glycoprotein of human parainfluenza virus type 3 : sequence analysis of variants selected with monoclonal antibodies which inhibit infectivity, hemagglutina tion, and neuraminidase activities. J. Virol. 61:1473-1477.

27. Davis, T. R., Munkenbeck Trotter, K., Granados, R. R. and Wood, H. A. 1992 Baculovirus expression of alkaline phosphatase as a reporter gene for evaluation of production, glycusylation and secretion. Bio/Technology 10:1148-1150

28. Wickman, T. J. and Nemerow, G. R. 1993. Optimization of growth methods and recombinant protein production in BTI-Tn-5B1-4 insect cells using the baculovirus expression system. Biotechnol. Prỏg. 9:25-30.

29. Hendrickson, K. J. and Portner, A. 1990. Antibody response in children to antigen sites on human PIV-3 HN:correlation with known epitopes mapped by monoclonal antibodies. Vaccine 8:75-80.

30. Murphy, B. R., Sotnikov, A., Paradiso, P. R., Hildreth, S. W. Jenson, A. B. Baggs, R. B., Lawrence, L., Zubak, J. J., Chanock, R. M., Beeler, J. A. and Prince, G. A. 1989. Immunization of cotton rats with the fusion (F) and large (G) glycoproteins of respiratory syncytial virus (RSV) protects against RSV challenge without potentiating RSV disease. Vaccine 7:533-540.

31. Ambrose M. W. Wyde, P. R. Ewasyshyn, M. E., Bonneau, A-M., Caplan, B. Meyer, H. L. and Klein, M. H. 1991. Evaluation of the immunogenicity and protective efficacy of a candidate parainfluenza type 3 subunit vaccine in cotton rats. Vaccine 9:505-511.

32. Luckow, V. A. and Summers, M. D. 1988. Trends in the development of baculovirus expression vectors. Bio/Technology 6:47-55.

33. Prince, G. A., Jenson, A. B., Hemming, V. G., Murphy, B. R., Walsh, E. E. Horswood, R. L., and Chanock, R. M. 1987. Enhancement of respiratory syncytial virus pulmonary pathology in cotton rats by prior intramuscular inoculation of formalin-inactivated virus. J. Virol. 61:3855-3861.

34. Kakuk, T. J., Soike, K. Brideau, R. J., Zaya, R. M., Cole, S. L., Zhang, J. Y. Roberts, E. D., Wells, P. A., and Wathen, M. W. 1993. A human respiratory syncytial virus (RSV) primate model of enhanced pulmonary pathology induced with a formalin-inactivated RSV vaccine but not a recombinant FG subunit vaccine. J. Infect. Dis. 167:553-561.

35. Hattori, M. and Sakaki, Y. 1986. Dideoxy sequencing method using denatured plasmid templates. Anal. Biochem. 152:232-238.

36. Summers, N. D. and Smith, G. E. 1987. A manual of methods for baculovirus vectors and insect cell culnure procedures. Texas Agricultural Experiment Station, Bulletin 1555.

37. Ewasyshyn, M. Caplan, B. Bonneau, A.-M. Scollard, N., Graham, S., Usman, S. and Klein, M. 1992. Comparative analysis of the immunostimulatory properties of different adjuvants on the immunogenicity of a prototype parainfluenza virus type 3 subunit vaccine. Vaccine 10:412-420.

38. Galinski, M. S., Mink, M. A. and Pons, M. 1987. Molecular cloning and sequencing analysis of the human parainfluenza 3 virus genes encoding the surface glycoproteins, $\mathrm{F}$ and $\mathrm{HN}$. Virus Research 8:205-215.

39. Laemmli, U. K. 1970. Cleavage of structural proteins during the assembly of the head of bacteriophage T4. Nature 226:680-685

40. Chanock, R. M. 1985. Parainfluenza viruses, p. 611-632. In: Diagnostic Procedures for Viral, Rickettsial and Chlamydial Infections. Lennette, E. H. and Schmidt, N. J. (Eds.). American Public Health Assoc., Washington, D.C 